\title{
Comparison of Public Health Nurse's Lifestyle Counseling Skills for Clients with Different Readiness of Behavior Changes in Primary Care Settings
}

\author{
Keiko Koide1, Reiko Okamoto ${ }^{2}$, Mari Okada ${ }^{3}$ \\ ${ }^{1}$ Faculty of Education, Shitennoji University, Osaka, Japan \\ ${ }^{2}$ Division of Health Sciences, Graduate School of Medicine, Osaka University, Osaka, Japan \\ ${ }^{3}$ Faculty of Health and Welfare, Prefectural University of Hiroshima, Hiroshima, Japan \\ Email: keiko@shitennoji.ac.jp
}

How to cite this paper: Koide, K., Okamoto, R. and Okada, M. (2017) Comparison of Public Health Nurse's Lifestyle Counseling Skills for Clients with Different Readiness of Behavior Changes in Primary Care Settings. Health, 9, 921-929.

https://doi.org/10.4236/health.2017.96065

Received: April 10, 2017

Accepted: June 16, 2017

Published: June 19, 2017

Copyright $\odot 2017$ by authors and Scientific Research Publishing Inc.

This work is licensed under the Creative Commons Attribution-NonCommercial International License (CC BY-NC 4.0).

http://creativecommons.org/licenses/by-nc/4.0/

\begin{abstract}
Purpose: Public health nurses (PHNs) are required to assess the readiness of the clients and provide lifestyle counseling accordingly. The purpose of this study was to compare the lifestyle counseling provided for clients with different levels of readiness based on self-evaluations and independent assessment. Methods: Participants were PHNs with 10 years' experience or less. Lifestyle counseling skills were measured through a simulated counseling session in a primary setting lasting up to 30 minutes, followed by a review session, where the participant provided self-evaluations, and the simulated client provided others-evaluations, of the session. The simulated clients played the role of clients at either the precontemplation or contemplation stage of preparedness as per the stages of behavior change theory. Results: The self-evaluation results showed that the mean scores for five of the six skill categories, are lower in the precontemplation-stage client cases than in the contemplation-stage client cases, and significantly so for two skill categories. The others-evaluations showed significantly lower mean scores for all skill categories in the precontemplation cases than in the contemplation cases. Conclusion: The PHNs and simulated clients agreed that lifestyle counseling skills were inadequate for the precontemplation cases, as compared with the contemplation cases. The lifestyle counseling skills of PHNs with less experience may not be well-adjusted to the readiness of the client, indicating difficulties in supporting less prepared clients.
\end{abstract}

\section{Keywords}

Skills in Lifestyle Counseling, Readiness of Behavior Change, Public Health 
Nursing, Lifestyle-Related Disease

\section{Introduction}

Healthy lifestyle habits including regular exercise, healthy diet, no smoking and moderate alcohol consumption are major vital factors in preventing lifestyle diseases such as cardiovascular disease and diabetes [1] [2] [3]. Primary care providers are required to give effective counseling to clients to improve their lifestyle habits to healthy ones. Systematic reviews of lifestyle counseling intended to promote a healthy lifestyle report the limited effectiveness of such counseling provided by nurses and primary care providers [4] [5], and highlight the necessity of leveraging health behavior theories in order to improve the effectiveness of lifestyle counseling [6].

Japan has introduced a health checkup process for adults aged 40 and over, aimed at reducing the numbers of actual and potential patients of lifestyle diseases including obesity. This process provides lifestyle counseling for those who are found to be at high risk for developing lifestyle diseases based on the checkup result, in order to help them improve their lifestyle. The counselors are mainly public health nurses (PHNs) working for health centers or occupation/ medical checkup institutions.

The clients required to improve their lifestyle under this process have different levels of readiness, which are often not high. Thus, PHNs are required to assess the readiness of the clients and provide counseling accordingly. The stages of behavior change theory classify the readiness of the client into five stagesprecontemplation, contemplation, preparation, action and maintenance-and defines their characteristics and support methods [7] [8]. This theory has often been used for health counseling and educational programs for lifestyle improvement [9] [10], as well as for assessing the achievement levels of such programs [11] [12]. Thus, PHNs need to leverage the stages of behavior change theory in providing lifestyle counseling. In Japan, however, no study to date has assessed lifestyle counseling skills by stage of change, making it impossible to gain any insight into how PHNs are adapting their lifestyle counseling practice to the readiness of the client.

This study identifies the characteristics of the PHNs' counseling skills for the clients, by comparing the skills for the clients with different readiness of behavior changes, precontemplation and contemplation, based on self-evaluation and others-evaluation. The significance of this study lies in obtaining suggestions for adjusting lifestyle counseling to the readiness of the client.

\section{Methods}

\subsection{Study Design}

This study was designed as a cross-sectional study. 


\subsection{Participants}

This study used baseline data from a lifestyle counseling skills improvement program [13]. The purpose of this program was to improve the lifestyle counseling skills of PHNs in encouraging clients with a high risk of lifestyle diseases to correct their habits. The inclusion criteria were PHNs with 10 years' experience or less, and the exclusion criteria were those who could not participate in the entire 4-day program. This intervention study was conducted from August to December 2012. Participants recruited by municipalities and medical checkup institutions in and around Okayama Prefecture, and Japan Health Insurance Association, in response to our request for cooperation.

We obtained written consent from the participants after providing explanations orally and in writing about the study. All studies were approved by the Research Ethics Committee of the Graduate School of Health Science at the University of Okayama (approval number T12-01).

\subsection{Data Collection}

Demographic information of participants was collected, including gender, age, PHNs' experience, place of work, and education. Lifestyle counseling skills were defined as "skills necessary for Japanese PHNs to be effective in encouraging a change in health behavior", identified in a previous study [14]. Those 17 skills were classified into six categories: three skills to build relationships with the client, four skills to assess the condition of the client, three skills to increase interest in and commitment to the change of behavior, two skills to link actual lifestyles with health needs, three skills to link health challenges with actual lifestyles, and two skills to raise confidence in the change of behavior [14]. Each skill category was assessed on a scale of 1-5:1 for "Unsatisfactory", 2 for "Rather unsatisfactory", 3 for "Do not know", 4 for "Rather satisfactory" and 5 for "Satisfactory".

Lifestyle counseling skills were measured through a simulated counseling session in a primary setting lasting up to 30 minutes a total of 2 times, followed by a review session, where the participant provided self-evaluations, and the simulated client provided others-evaluations, of the session. The simulated clients played the role of clients at either the precontemplation (no intention to change behavior within the next six months) or contemplation (intention to change behavior within 30 days) stage of preparedness as per the stages of behavior change theory [7] [8]. Necessary information was prepared for role-playing, including the time series of checkup results and medical interview sheets. The participants were measured lifestyle counseling skills in engaging with clients at different levels of preparedness.

The role of simulated clients was played by those with experience in playing the role of clients for lifestyle counseling, and in the objective structured clinical examination of medical students at organizations providing such training. The simulated clients were 8 women. A preliminary meeting was held with the simulated clients regarding the assessment method and role making. 


\subsection{Data Analysis}

The appropriateness of calculating total scores through factor analysis(principal factor method) of baseline responses by category was verified. For all categories, the results indicated that the eigenvalue of the first factor exceeded 1 (mean of 1.64 , range of $1.22-2.31$ ) while that of the second factor was significantly lower, only reaching 0.08 at a maximum, with a factor loading of 0.44 or over. Moreover, Cronbach's alpha coefficient was $0.86(0.74-0.95)$ in the mean, which allowed us to utilize total scores by category. For analysis purposes, the mean score of each skill category in engaging with a client in the precontemplation and contemplation stages based on both self-evaluation and independent evaluation was calculated. We conducted a paired t-test to compare he score for each skill category by stage of change. We used the statistical package SAS System for Windows Version 9.3 for analysis, at the significance level of 0.05 .

\section{Results}

\subsection{Characteristics of Participants}

There were 22 participants, whose characteristics are shown in Table 1. Most of the participants were women (90.9\%), with a mean (SD) PHN experience of 3.5 years (2.7). There were 6 people (27.3\%) with less than 2 years of PHN experience, 5 (22.7\%) with 2 to 3 years, $2(9.1 \%)$ with 3 to 4 years, $5(22.7 \%)$ with 4 to 7 years, and $4(18.2 \%)$ with 7 to 10 years. 12 participants (54.5\%) worked for a municipality, followed by six occupational PHNs (27.3\%) and four PHNs working for a hospital (18.2\%).

\subsection{Comparison of Self-Evaluations Scores on Lifestyle Counseling for Clients at the Precontemplation and Contemplation Stages}

Table 2 shows self-evaluations scores by skill category. With regard to the skills

Table 1. Characteristics of participants.

\begin{tabular}{|c|c|c|c|}
\hline & & Number & $\%$ \\
\hline \multicolumn{4}{|l|}{ Gender } \\
\hline Male & & 2 & 9.1 \\
\hline Female & & 20 & 90.9 \\
\hline Age & Mean \pm SD & \multicolumn{2}{|l|}{$28.7 \pm 4.0$} \\
\hline PHNs' experience & Mean \pm SD & \multicolumn{2}{|l|}{$3.5 \pm 2.7$} \\
\hline \multicolumn{4}{|l|}{ Place of work } \\
\hline Health center & & 12 & 54.6 \\
\hline Occupation & & 6 & 27.3 \\
\hline Hospital & & 4 & 18.2 \\
\hline \multicolumn{4}{|l|}{ Education } \\
\hline College graduate & & 15 & 68.2 \\
\hline Junior college/some college & & 7 & 31.8 \\
\hline
\end{tabular}


to engage with clients at the precontemplation stage, the scores were lower than those regarding clients at the contemplation stage, except for skills to assess the condition of the client. The score for skills to build relationships with the client was significantly lower at the precontemplation stage (9.6) than at the contemplation stage (10.5). Likewise, the score for skills to raise confidence in the change of behavior was significantly lower at the precontemplation stage (4.1) than at the contemplation stage (5.5).

\subsection{Comparison of Others-Evaluations Scores on Lifestyle Counseling for Simulated Clients at the Precontemplation and Contemplation Stages}

Table 3 presents mean others-evaluations scores by skill category. The mean scores for all skill categories in the case of precontemplation clients were significantly lower than the mean scores for clients at the contemplation stage.

Table 2. Comparison of self-evaluations on lifestyle counseling for simulated clients at precontemplation and contemplation stages.

\begin{tabular}{|c|c|c|c|c|}
\hline & \multirow{2}{*}{ Range } & Precontemplation & Contemplation & \multirow{2}{*}{$\begin{array}{c}P \\
\text { value }\end{array}$} \\
\hline & & Mean \pm SD & Mean \pm SD & \\
\hline Skills to build relationships with the client & $5-15$ & $9.6 \pm 1.7$ & $10.5 \pm 1.7$ & 0.02 \\
\hline Skills to assess the condition of the client & $5-20$ & $11.9 \pm 2.6$ & $11.9 \pm 2.7$ & 0.99 \\
\hline $\begin{array}{l}\text { Skills to increase interest in and commitment } \\
\text { to the change of behavior }\end{array}$ & $5-15$ & $7.5 \pm 2.6$ & $8.4 \pm 2.3$ & 0.10 \\
\hline Skills to link actual lifestyles with health needs & $5-10$ & $5.8 \pm 1.6$ & $6.0 \pm 1.7$ & 0.54 \\
\hline $\begin{array}{l}\text { Skills to link health challenges with actual } \\
\text { lifestyles }\end{array}$ & $5-15$ & $6.5 \pm 2.7$ & $7.6 \pm 2.6$ & 0.14 \\
\hline $\begin{array}{l}\text { Skills to raise confidence in the change of } \\
\text { behavior }\end{array}$ & $5-10$ & $4.1 \pm 1.9$ & $5.5 \pm 1.9$ & $<0.01$ \\
\hline
\end{tabular}

Table 3. Comparison of others-evaluations on lifestyle counseling for simulated clients at precontemplation and contemplation stages.

\begin{tabular}{|c|c|c|c|c|}
\hline & & Precontemplation & Contemplation & $P$ \\
\hline & & Mean \pm SD & Mean \pm SD & value \\
\hline Skills to build relationships with the client & $5-15$ & $11.0 \pm 2.2$ & $13.3 \pm 13.3$ & $<0.01$ \\
\hline Skills to assess the condition of the client & $5-20$ & $13.6 \pm 2.4$ & $16.5 \pm 16.5$ & $<0.01$ \\
\hline $\begin{array}{l}\text { Skills to increase interest in and commitment } \\
\text { to the change of behavior }\end{array}$ & $5-15$ & $9.7 \pm 1.2$ & $11.7 \pm 11.7$ & $<0.01$ \\
\hline Skills to link actual lifestyles with health needs & $5-10$ & $7.0 \pm 1.1$ & $7.7 \pm 7.7$ & 0.09 \\
\hline $\begin{array}{l}\text { Skills to link health challenges with actual } \\
\text { lifestyles }\end{array}$ & $5-15$ & $9.7 \pm 2.5$ & $12.0 \pm 12.0$ & $<0.01$ \\
\hline $\begin{array}{l}\text { Skills to raise confidence in the change of } \\
\text { behavior }\end{array}$ & $5-10$ & $6.5 \pm 2.0$ & $8.4 \pm 8.4$ & $<0.01$ \\
\hline
\end{tabular}




\section{Discussion}

This study conducted simulated initial lifestyle counseling sessions for selfevaluations of counseling skills by PHNs with 10 years' experience or less, and others-evaluations by the simulated clients. The results of self-evaluations indicated that the mean scores for five of the six skill categories, excluding the skills to assess the condition of the client, were significantly lower at the precontemplation stage than at the contemplation stage, whereas the result of others-evaluations pointed to lower scores for all skill categories at the precontemplation stage than at the contemplation stage. Thus, it was found that both the PHNs and simulated clients considered lifestyle counseling at the precontemplation stage as inadequate in comparison with that at the contemplation stage. Yamashita and Haruyamaverified the short-term effectiveness of lifestyle counseling in Japan pointed to significant reductions in weight and abdominal girth in the intervention group [15] [16], indicating that the quality of counseling is reasonable. However, when the simulated clients are females, lifestyle counseling by less experienced PHNs may be lacking in responsiveness to client's readiness.

A study on practice nurses' (PNs') motivational interviewing skills designed to improve lifestyle in a primary setting indicated inadequate support for less prepared patients at the precontemplation stage-a result consistent with the findings of this study [17]. The mean age of participants in Noordman et al. was 42, but the length of their experience as PNs was 4.5 years, comparable to the mean age of the PHNs participating in this survey. Although PNs in the Netherlands have different educational backgrounds from those of PHNs in Japan, the results indicated that challenges for less experienced PHNs in lifestyle counseling are centered on their approach to less prepared clients.

It has been said that lifestyle counseling leveraging the stages of behavior change theory should focus on increasing awareness of the issues and changing attitudes when it addresses clients at the precontemplation stage, and on the initiation of action through the identification of specific goals and skills when it addresses clients at the contemplation stage [12]. Thus, the results of this study show that clearly explaining the relationship between lifestyle and diseases to the client is a major challenge for PHNs with limited experience.

Self-evaluations in this study also revealed that the skills to raise confidence in the change of behavior were significantly lower for clients at the precontemplation stage than for those at the contemplation stage. During the simulated lifestyle counseling session, PHNs may have encouraged clients at the precontemplation stage to set objectives, triggering a negative response. This negative response from the clients may have prevented PHNs from feeling that they successfully provided the necessary support, hence the low self-evaluation of their confidence-raising skills.

Others-evaluations shows lower mean scores across the board at the precontemplation stage than at the contemplation stage. As demonstrated in a review of lifestyle counseling provided by doctors and nurses for weight reduction using the 5 A's (Assess, Advise, Agree, Assist and Arrange) model [18], the doctors 
most frequently Advise and Assess, and rarely Agree, Assist or Arrange, whereas the patients most prefer Assist and Arrange, pointing to a gap between practice and patient demand [19]. In our study, the simulated clients may have considered that the lifestyle counseling was less responsive to their demand at the precontemplation stage than at the contemplation stage.

Limits to this study include its small sample size as the participants had PHN experience of 10 years or less. In the future, study will need to secure a larger sample size and adjust for the difference in the affiliation and educational background among the participating PHNs. All simulated clients were female, and so PHN's lifestyle counseling skills could not be compared with those of men. In this study, we simulated initial lifestyle counseling sessions for self-evaluations and others-evaluations of counseling skills. We will still need to record actual lifestyle counseling sessions to analyze relevant skills. Yet, the significance of this study lies in elucidating the characteristics of lifestyle counseling by comparing the effectiveness of relevant skills for clients at different stages of preparedness precontemplation and contemplation.

\section{Conclusion}

By primary settings, this study compared the effectiveness of lifestyle counseling skills for clients at different stages of preparedness (precontemplation and contemplation) through self-evaluations by PHNs with 10 years' experience or less and others-evaluations by the simulated clients. The self-evaluations results showed that the mean scores for five of the six skill categories, excluding the skills to assess the condition of the client, are lower in the precontemplationstage client cases than in the contemplation-stage client cases, and significantly so for two skill categories: the skills to build relationships with the client and the skills to raise confidence in the change of behavior. The others-evaluations showed significantly lower mean scores for all skill categories in the precontemplation cases than in the contemplation cases. Thus, the PHNs and simulated clients agreed that lifestyle counseling skills were inadequate for the precontemplation cases, as compared with the contemplation cases. The lifestyle counseling skills of PHNs with less experience may not be well-adjusted to the preparedness of the client, indicating difficulties in supporting less prepared clients. Further research is required with a larger sample size.

\section{Acknowledgements}

We thank all PHNs who participated in the program. This research was supported by The Ministry of Health Labour and Welfare. Health Labour Sciences Research Grant. We have no conflict of interest to report on our relationships with any specific entity.

\section{References}

[1] Rahati, S., Shahraki, M., Arjomand, G. and Shahraki, T. (2014) Food Pattern, Lifestyle and Diabetes Mellitus. International Journal of High Risk Behaviors \& Addic- 
tion, 3, e8725. https://doi.org/10.5812/ijhrba.8725

[2] King, D.E., Mainous, A.G., Carnemolla, M. and Everett, C.J. (2009) Adherence to Healthy Lifestyle Habits in US Adults, 1988-2006. American Journal of Medicine, 122, 528-534. https://doi.org/10.1016/j.amjmed.2008.11.013

[3] Jakicic, J.M. and Otto, A.D. (2006) Treatment and Prevention of Obesity: What is the Role of Exercise? Nutrition Reviews, 64, 57-61. https://doi.org/10.1301/nr.2006.feb.S57-S61

[4] Noordman, J., van der Weijden, T. and van Dulmen, S. (2012) Communication-Related Behavior Change Techniques Used in Face-to-Face Lifestyle Interventions in Primary Care: A Systematic Review of the Literature. Patient Education and Counseling, 89, 227-244. https://doi.org/10.1016/j.pec.2012.07.006

[5] Fleming, P. and Godwin, M. (2008) Lifestyle Interventions in Primary Care: Systematic Review of Randomized Controlled Trials. Canadian Family Physician, 54, 1706-1713.

[6] Sargent, G.M., Forrest, L.E. and Parker, R.M. (2012) Nurse Delivered Lifestyle Interventions in Primary Health Care to Treat Chronic Disease Risk Factors Associated with Obesity: A Systematic Review. Obesity Reviews, 13, 1148-1171.

https://doi.org/10.1111/j.1467-789X.2012.01029.x

[7] Petrocelli, J.V. (2002) Processes and Stages of Change: Counseling with the Transtheoretical Model of Change. Journal of Counseling \& Development, 80, 22-30. https://doi.org/10.1002/j.1556-6678.2002.tb00162.x

[8] Prochaska, J.O. and Velicer, W.F. (1997) The Transtheoretical Model of Health Behavior Change. American Journal of Health Promotion, 12, 38-48. https://doi.org/10.4278/0890-1171-12.1.38

[9] Friedberg, J.P., Rodriguez, M.A., Watsula, M.E., Lin, I., Wylie-Rosett, J., Allegrante, J.P., Lipsitz, S.R., et al. (2015) Effectiveness of a Tailored Behavioral Intervention to Improve Hypertension Control: Primary Outcomes of a Randomized Controlled Trial. Hypertension, 65, 440-446. https://doi.org/10.1161/HYPERTENSIONAHA.114.03483

[10] Peterson, J.A. and Cheng, A.L. (2013) Physical Activity Counseling Intervention to Promote Weight Loss in Overweight Rural Women. Journal of the American Association of Nurse Practitioners, 25, 385-394. https://doi.org/10.1111/j.1745-7599.2012.00794.x

[11] Harris, M.F., Chan, B.C., Laws, R.A., Williams, A.M., Davies, G.P., Jayasinghe, U.W., et al. (2013) The Impact of a Brief Lifestyle Intervention Delivered by Generalist Community Nurses (CN SNAP Trial). BMC Public Health, 13, 375. https://doi.org/10.1186/1471-2458-13-375

[12] Steptoe, A., Kerry, S., Rink, E. and Hilton, S. (2001) The Impact of Behavioral Counseling on Stage of Change in Fat Intake, Physical Activity, and Cigarette Smoking in Adults at Increased Risk of Coronary Heart Disease. American Journal of Public Health, 91, 265-269. https://doi.org/10.2105/AJPH.91.2.265

[13] Koide, K., Okamoto, R., Nekoda, Y. and Okada, M. (2015) Effect on Public Health Nurses of a Reflection-based Health Guidance Skills Improvement Program. Journal of Japan Academy of Community Health Nursing, 17, 4-13.

[14] Koide, K., Okamoto, R., Kusano, E., Okada, M., Ono, M., Nekoda, Y., et al. (2014) Essential Skills of Public Health Nurses in the First Health Guidance to Encourage the Change of the Health Behavior for Preventing a Lifestyle-Related Disease in Japan. Journal of Shikoku Public Health Society, 59,103-113.

[15] Yamashita, A., Taguchi, K., Sasaki, K. and Nishida, H. (2011) Influence of Specific 
Health Guidance in Annual Medical Check-ups. Official Journal of Japan Society of Ningen Dock, 26, 590-594.

[16] Haruyama, Y., Muto, T., Nakate, M., Yamasaki, A. and Tarumi, F. (2012) Changes in Measurements Related to Metabolic Syndrome among Individuals with National Health Insurance after Specific Health Guidance. Nihon KoshuEiseiZasshi (Japanese Journal of Public Health), 59, 731-742.

[17] Noordman, J., de Vet, E., van der Weijden, T. and van Dulmen, S. (2013) Motivational Interviewing within the Different Stages of Change: An Analysis of Practice Nurse-Patient Consultations Aimed at Promoting a Healthier Lifestyle. Social Science and Medicine, 87, 60-67. https://doi.org/10.1016/j.socscimed.2013.03.019

[18] Whitlock, E.P., Orleans, C.T., Pender, N. and Allan, J. (2002) Evaluating Primary Care Behavioral Counseling Interventions: An Evidence-Based Approach. American Journal of Preventive Medicine, 22,267-284. https://doi.org/10.1016/S0749-3797(02)00415-4

[19] Sherson, E.A., Yakes Jimenez, E. and Katalanos, N. (2014) A Review of the Use of the 5 A's Model for Weight Loss Counselling: Differences between Physician Practice and Patient Demand. Family Practice, 31, 389-398. https://doi.org/10.1093/fampra/cmu020

\section{Submit or recommend next manuscript to SCIRP and we will provide best} service for you:

Accepting pre-submission inquiries through Email, Facebook, LinkedIn, Twitter, etc. A wide selection of journals (inclusive of 9 subjects, more than 200 journals)

Providing 24-hour high-quality service

User-friendly online submission system

Fair and swift peer-review system

Efficient typesetting and proofreading procedure

Display of the result of downloads and visits, as well as the number of cited articles

Maximum dissemination of your research work

Submit your manuscript at: http://papersubmission.scirp.org/

Or contact health@scirp.org 